\title{
Erratum to: Pycnogonida from the Bellingshausen and Amundsen seas: taxonomy and biodiversity
}

\author{
Tomás Munilla $\cdot$ Anna Soler-Membrives
}

Published online: 22 October 2014

(C) Springer-Verlag Berlin Heidelberg 2014

\section{Erratum to: Polar Biol}

\section{DOI 10.1007/s00300-014-1585-8}

The name of the new species Nymphon nakamurai described in the paper entitled "Pycnogonida from the
Bellingshausen and Amundsen Seas: taxonomy and biodiversity" (DOI: 10.1007/s00300-014-1585-8) was already held by a pycnogonid species described by Stock (1994). Therefore, Nymphon nakamurai is an invalid name for this new species, and the correct name is Nymphon koichiroi.

The online version of the original article can be found under doi:10.1007/s00300-014-1585-8.

T. Munilla $\cdot$ A. Soler-Membrives $(\square)$

Unitat de Zoologia, Universitat Autònoma de Barcelona,

08193 Bellaterra, Barcelona, Spain

e-mail: Anna.Soler@uab.cat 